\title{
A novel controllable crowbar based on fault type protection technique for DFIG wind energy conversion system using adaptive neuro-fuzzy inference system
}

\author{
Omar Noureldeen ${ }^{*}$ (1) and I. Hamdan(D)
}

\begin{abstract}
This paper proposes a novel controllable crowbar based on fault type (CBFT) protection technique for doubly fed induction generator (DFIG) wind energy conversion system connected to grid. The studied system consists of six DFIG wind turbines with a capacity of $1.5 \mathrm{MW}$ for each of them. The operation mechanism of proposed technique is used to connect a set of crowbar resistors in different connection ways via activation of controllable circuit breakers (CBs) depending on the detected fault type. For each phase of DFIG, a crowbar resistor is connected in parallel with a controllable CB and all of them are connected in series to grid terminals. The adaptive neuro-fuzzy inference system (ANFIS) networks are designed to detect the fault occurrence, classify the fault type, activate the CBs for crowbar resistors associated with faulted phases during fault period, and deactivate them after fault clearance. The effectiveness of proposed CBFT protection technique is investigated for different fault types such as symmetrical and unsymmetrical faults taking into account the single-phase to ground fault is the most frequently fault type that occurs in power systems. Also, a comparison between the behaviours of studied system in cases of using traditional parallel rotor crowbar, classical outer crowbar, and proposed CBFT protection techniques is studied. The fluctuations of DC-link voltage, active power, and reactive power for studied system equipped with different protection techniques are investigated. Moreover, the impacts of different crowbar resistance values on the accuracy of proposed technique are studied. The simulation results show that, the proposed technique enhances the stability of studied wind turbine generators and contributes in protection of their components during faults.
\end{abstract}

Keywords: ANFIS networks, Crowbar, Power electronic converters, DFIG wind turbines, Fault types

\section{Introduction}

In the last few decades, Energy problems are increased rapidly due to fast depletion of the fossil fuel and its highly cost, thus renewable energy plays an alternative way in order to overcome the expected power crisis. Wind energy is one of the renewable energy sources, where it is clean, plentiful, environmentally friendly, and widely distributed. Also, it reduces the toxic atmospheric and not producing greenhouse gas emissions [1]. Wind energy conversion system converts the wind energy into mechanical energy based on the principle of aerodynamic through the turbine, then the mechanical

\footnotetext{
* Correspondence: omar_noureldeen@svu.edu.eg

Department of Electrical Engineering, Faculty of Engineering, South Valley University, Qena 83523, Egypt
}

\section{Springer Open}

(c) The Author(s). 2018 Open Access This article is distributed under the terms of the Creative Commons Attribution 4.0 International License (http://creativecommons.org/licenses/by/4.0/), which permits unrestricted use, distribution, and reproduction in any medium, provided you give appropriate credit to the original author(s) and the source, provide a link to the Creative Commons license, and indicate if changes were made.

energy is converted into electrical energy based on the principle of electromagnetic induction through the generator $[2,3]$. The usage of DFIG is receiving high attention regarding wind turbines connected to electrical grid. The DFIG is an induction machine with a wound rotor, where the stator windings are connected to grid and the rotor windings are connected to bidirectional converters, thus the stator and rotor windings are connected to grid bus, hence the derived term of 'doubly fed' $[4,5]$. The DFIG is sensitive to voltage dips during grid fault, subsequently the high current is passing through the power electronic converters [6]. This situation needs special attention to block converters and disconnect DFIG from the grid to avoid any risks [7-9]. The fault ride through (FRT) or low voltage ride through 
(LVRT) is a term that refers to the wind turbines must be remain connected to grid during faults [10]. Also, all requisites for safe operation of DFIG components is required, because of rotor current will become very large during grid faults [11]. Therefore, DFIG requires a protection system called crowbar techniques that usually adopted for limiting the high currents in order to improve the fault handling capacity and protection requirements [12]. The crowbar protection technique is necessary to avoid a disconnecting of DFIG wind turbines during grid faults. Many researches introduce different crowbar protection techniques such as series crowbar resistors connected with stator windings, parallel crowbar resistors connected with rotor windings, and outer crowbar resistors connected between the DFIG terminals and electrical grid [10-18]. Traditionally, the parallel crowbar is engaged to rotor windings, where the converters are disabled and the DFIG is converted to a singly fed induction generator. Therefore, the usage of traditional parallel rotor crowbar technique is unsatisfactory for LVRT grid requirements. Recently, this problem is solved by using the outer crowbar technique that designed in $[14,15]$. Typically, only $5 \%$ of the faults occurrences in power systems are a three-phase fault with or without ground. Regarding the unbalanced faults, $80 \%$ are single-phase to ground fault and $15 \%$ are double-phase faults with or without ground, where these faults often can be deteriorated to three-phase fault $[19,20]$. It is clear that, the single-phase to ground fault is most frequently fault type that occurs in electrical power system. Most researchers concentrate on the studying of DFIG wind turbine behaviours in case of three-phase to ground fault [9-18]. This paper proposes a novel controllable CBFT protection technique driven by ANFIS for studied DFIG wind turbines. The ANFIS is a type of artificial intelligent algorithms that involves the two algorithms of fuzzy logic system and neural network system [21-23]. Moreover, the ANFIS can be designed and employed to get the benefits of both fuzzy logic and neural structure in one scheme [24, 25]. The proposed protection technique is structured as a combination of three crowbar resistors that connected to wind turbine generator terminals. The combination resistors are connected in different ways which they are controlled by ANFIS networks. The accuracy of proposed CBFT protection technique is studied for different fault types of symmetrical and unsymmetrical faults such as single-phase, double-phase, and three-phase to ground faults. In addition, the behaviours of studied DFIG wind turbines equipped with classical outer crowbar and proposed ANFIS CBFT protection techniques during different fault types are investigated. Also, a comparison with traditional parallel rotor crowbar protection technique as introduced in [10-14] is added to demonstrate the effectiveness of the proposed technique. Moreover, the impacts of different crowbar resistor values on the accuracy of proposed protection technique equipped with studied system are investigated. The rest of this paper is organized as follows: Section 2 presents the description of DFIG wind energy conversion system. Section 3 describes the structure of ANFIS network. Section 4 introduces the Methods, where the methodology of classical outer crowbar and proposed CBFT protection techniques are driven by ANFIS networks. In Section 5, the simulation results are demonstrated to show the effectiveness of proposed technique. Finally, the paper is concluded in Section 6.

\section{Description of DFIG wind energy conversion system}

The mechanical power captured by wind turbines is converted into electrical power through DFIG, then it is transmitted to utility grid through the converters and stator. Therefore, the whole system structure that converts the wind power into useful electrical power is known as wind energy conversion system. The general structure of grid tied DFIG wind turbine is illustrated in Fig. 1. The mathematical model of wind energy conversion system is discussed in [25-30] and presented in the following subsections.

\subsection{Wind turbine model}

The wind turbine is used to convert the kinetic energy of wind into mechanical energy [25-30]. The power that can be extracted from the wind is given as follows:

$$
P_{w}=\frac{1}{2} \rho \pi R_{b}^{2} V_{w}^{3}
$$

where $P_{w}$ is the wind power, $\rho$ is the air flow density, $R_{b}$ is the blade radius, and $V_{w}$ is the wind speed. The perfect wind turbines cannot extract all the power available in the wind. The mechanical power that can be extracted by wind turbine is a function of power coefficient and it is given as follows:

$$
P_{m}=\frac{1}{2} C_{P}(\lambda, \beta) \rho \pi R_{b}^{2} V_{w}^{3}
$$

where $P_{m}$ is the mechanical power, $C_{P}$ is the power coefficient, $\lambda$ is the tip speed ratio, and $\beta$ is the pitch angle.

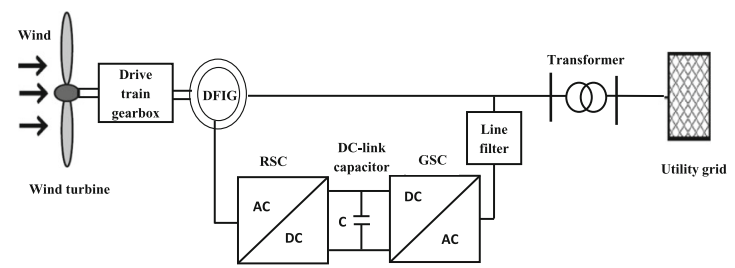

Fig. 1 Schematic diagram of grid tied DFIG wind turbine 
The turbine mechanical torque is the ratio of output mechanical power to shaft speed and can be described as follows:

$$
\begin{aligned}
& T_{m}=\frac{P_{m}}{\omega_{t}}=\frac{C_{P}(\lambda, \beta) \pi \rho R_{b}^{3} V_{w}^{2}}{2 \lambda} \\
& \lambda=\frac{\omega_{t} R_{b}}{V_{w}}
\end{aligned}
$$

where $T_{m}$ is the mechanical torque, and $\omega_{t}$ is the turbine rotor speed.

The power coefficient $C_{P}$ represents the fraction of wind power captured by the turbine and can be expressed as:

$$
C_{P}(\lambda, \beta)=\left(0.73\left(\frac{151}{\lambda_{i}}\right)-0.002 \beta-13.2\right) e^{\left(\frac{-18.4}{\lambda_{i}}\right)}
$$

where $\lambda_{i}$ is the middle variable that can be expressed as follows:

$$
\lambda_{i}=\left(\left(\frac{1}{\lambda+0.08 \beta}\right)-\left(\frac{0.035}{\beta^{3}+1}\right)\right)^{-1}
$$

\subsection{DFIG model}

The DFIG is an adjustable speed induction machine which is widely used in wind turbines [25-30]. The model of DFIG system in an appropriate $\mathrm{d}$-q reference frame is given as follows:

$$
\begin{aligned}
& u_{d s}=R_{s} i_{d s}-\omega_{s} \psi_{q s}+\frac{d \psi_{d s}}{d t} \\
& u_{q s}=R_{s} i_{q s}+\omega_{s} \psi_{d s}+\frac{d \psi_{q s}}{d t} \\
& u_{d r}=R_{r} i_{d r}-\omega_{r} \psi_{q r}+\frac{d \psi_{d r}}{d t} \\
& u_{q r}=R_{r} i_{q r}+\omega_{r} \psi_{d r}+\frac{d \psi_{q r}}{d t}
\end{aligned}
$$

where $u_{d s}, u_{q s}, u_{d n} u_{q n} i_{d s}, i_{q s}, i_{d n} i_{q n} \psi_{d s}, \psi_{q s}, \psi_{d n}$ and $\psi_{q r}$ are the d-q components of stator and rotor voltages, currents, and fluxes linkages, $R_{s}$ and $R_{r}$ are the resistances of stator and rotor windings, $\omega_{s}$ and $\omega_{r}$ are the angular frequencies of stator and rotor currents.

The total active power and reactive power for both stator and rotor sides can be expressed respectively as follows:

$$
\begin{aligned}
& P=P_{s}+P_{r} \\
& Q=Q_{s}+Q_{r}
\end{aligned}
$$

where $P$ is the total active power, $P_{s}$ is the stator active power, $P_{r}$ is the rotor active power, $Q$ is the total reactive power, $Q_{s}$ is the stator reactive power, and $Q_{r}$ is the rotor reactive power.

\subsection{AC/DC/AC converters}

The $\mathrm{AC} / \mathrm{DC} / \mathrm{AC}$ converters equipped with bidirectional IGBTs are connected between rotor windings and grid bus. The power that transmitted via converters is typically about $25-30 \%$ of generator nominal power [4]. The rotor side converter (RSC) and grid side converter (GSC) are voltage sourced converters that use forced commutated power electronic components to synthesize AC voltage from DC voltage source. The shunt capacitor that connected to DC side works as a DC voltage source. The controllers of converters are divided into two main parts such as RSC controller and GSC controller, where the RSC is used to control active power and reactive power (or voltage level), while the GSC is used to control DC-link voltage and reactive power.

\section{The structure of ANFIS network}

ANFIS network is a data learning algorithm that uses the fuzzy logic system to transform the given inputs into a desired output via highly interconnected artificial neural network processing elements and information connections, which it is weighted to map the numerical inputs into output. The structure of ANFIS network is based on Takagi-Sugeno fuzzy inference system, thus fuzzy inference system is described by a set of fuzzy IF-THEN rules that have adapted via learning algorithm of neural network [2125]. The fuzzy rules are presented based on zero order Takagi-Sugeno model as in Eq. (13) or first order Takagi-Sugeno model as in Eq. (14). The rules of the inputs $(x, y)$ and the output $(\mathrm{z})$ can be described as follows:

$$
\begin{aligned}
& \text { Rule } i \text { : IF } x \text { is } A_{j} \text { and } y \text { is } B_{k} \operatorname{THEN} z_{i}=r_{i} \\
& \text { Rule } i: \operatorname{IF} x \text { is } A_{j} \text { and } y \text { is } B_{k} \operatorname{THEN} z_{i} \\
& \quad=p_{i} x+q_{i} y+r_{i}
\end{aligned}
$$

where $A_{j}$ and $B_{k}$ are the fuzzy sets belongs to inputs $x$ and $y$ respectively, $j=(1,2, \ldots ., m)$ and $k=(1,2, \ldots . ., n)$ indicate the number of membership functions that defined by the indicated fuzzy input variables, $z_{i}$ is constant or linear consequent function, $\left(p_{i} q_{i}\right.$ and $\left.r_{i}\right)$ are the consequent parameters, and $i=(1,2, \ldots ., m \times n)$ indicates the number of rules. The ANFIS network architecture consists of five layers. The first layer of this architecture is named as the fuzzification layer. Each input node in this layer is an adaptive node which produce membership grade of linguistic label with a node function that may be triangular membership function, gaussian membership function, or any membership functions.

$$
\begin{aligned}
& O_{1, j}=\mu A_{j}(x) \\
& O_{1, k}=\mu B_{k}(y)
\end{aligned}
$$


where $\left(\mu \mathrm{A}_{\mathrm{j}}, \mu \mathrm{B}_{\mathrm{k}}\right)$ are membership function degrees and $\left(o_{1, j}, o_{1, k}\right)$ are the outputs of node $j, k$ for layer 1 .

The second layer is named as the rule layer, where every node in this layer is a fixed node. Each rule's firing strength is calculated with the membership function degrees that are coming from the previous layer. This layer involves fuzzy operators, where it uses the AND or product operator to fuzzify the inputs. The output of this layer can be represented as follows:

$$
O_{2, i}=w_{i}=\mu A_{j}(x) \times \mu B_{k}(y)
$$

where the output signal $w_{i}$ denotes the firing strength of the associated rule and $o_{2, i}$ is the output of node $i$ for layer 2. The third Layer which is named as the normalization layer, where every node is a fixed node and the normalized firing strengths for each rule are getting from the previous layer. The output of this layer can be calculated as follows:

$$
O_{3, i}=\overline{w_{i}}=\frac{w_{i}}{\sum_{t=1}^{m \times n} w_{t}}
$$

where the output signal $\overline{w_{i}}$ denotes the normalized firing strengths and $o_{3, i}$ is the output of node $i$ for layer 3. The fourth layer is the defuzzification layer, where every node in this layer is an adaptive node with a function node. The output value for each rule is calculated by using the value of normalized firing strength from previous layer and polynomial of Takagi-Sugeno model. The output of this layer is given as follows:

$$
O_{4, i}=\overline{w_{i}} \times z_{i}
$$

where $o_{4, i}$ is the output of node $i$ for layer 4 .

The fifth layer is called sum layer, where it is a fixed node and represented by a single summation node. The ANFIS output is calculated by collecting the overall output values belong to the incoming signals of each rule in the previous layer. The overall output of ANFIS network is given as follows:

$$
O_{5, i}=z=\sum_{i}\left(\overline{w_{i}} \times z_{i}\right)=\frac{\sum_{i} w_{i} \times z_{i}}{\sum_{i} w_{i}}
$$

where $o_{5, i}$ is the output of node $i$ for layer 5 .

\section{Methods}

In the following subsections, the methodology of classical operation mechanism of outer crowbar protection technique and new operation mechanism of proposed controllable CBFT protection technique based on ANFIS network is presented. The ANFIS network is trained and tested using different measured data of studied system in normal and abnormal cases. It is trained based on measured values of voltage and current for each phase during different fault types, then after training process the network is tested for different fault cases other than that are used in training. The input layer of ANFIS has two input signals such as phase voltage and current, which these inputs are processing through internal layers of network and trained via optimization algorithm to get the perfect control signal of output layer. The trained ANFIS network is applied in protection techniques to detect various fault cases, where the output of ANFIS network is logical state (0 or 1$)$. This output is 0 during normal operation condition and 1 during fault condition. The selected parameters of ANFIS structure for classical outer crowbar and proposed CBFT protection techniques are given in Table 1.

\subsection{The methodology of classical outer crowbar protection technique driven by ANFIS}

The classical outer crowbar protection technique consists of three resistors which are connected in parallel with three-phase $\mathrm{CB}[14,15]$. In normal conditions, the $\mathrm{CB}$ remains closed and the currents are passing through it. During fault occurrence, the fault is detected via ANFIS and the CB is opened, then the currents will be passing through crowbar resistors. Figure 2 shows schematic diagram of DFIG wind turbine equipped with classical outer crowbar protection technique. This technique uses one ANFIS network to detect any fault type occurs on phases a, b, and c, then a control signal will be sending to open the $\mathrm{CB}$ during fault period and reclose it after fault clearance for any fault types. Figure 3 shows the ANFIS structure of classical protection technique for studied system. The inputs of ANFIS are the measured root mean square (RMS) values of the three phase voltages and currents at DFIG terminals, where these inputs are $(U a b c, I a b c)$. The ANFIS output is a control signal for $\mathrm{CB}$ to activate or deactivate it. The flowchart of classical protection technique during fault occurrence is illustrated in Fig. 4. The ANFIS network of classical

Table 1 Parameters of each ANFIS structure

\begin{tabular}{ll}
\hline Parameters & Values/types \\
\hline Input layer & 2 \\
Output layer & 1 \\
Input membership function number & 3 \\
Rules & 9 \\
Input membership function shape & Gaussian \\
Output membership function shape & Constant \\
Optimization method & Hybrid algorithm \\
Training epochs & 300 \\
Error of testing & 0 \\
\hline
\end{tabular}




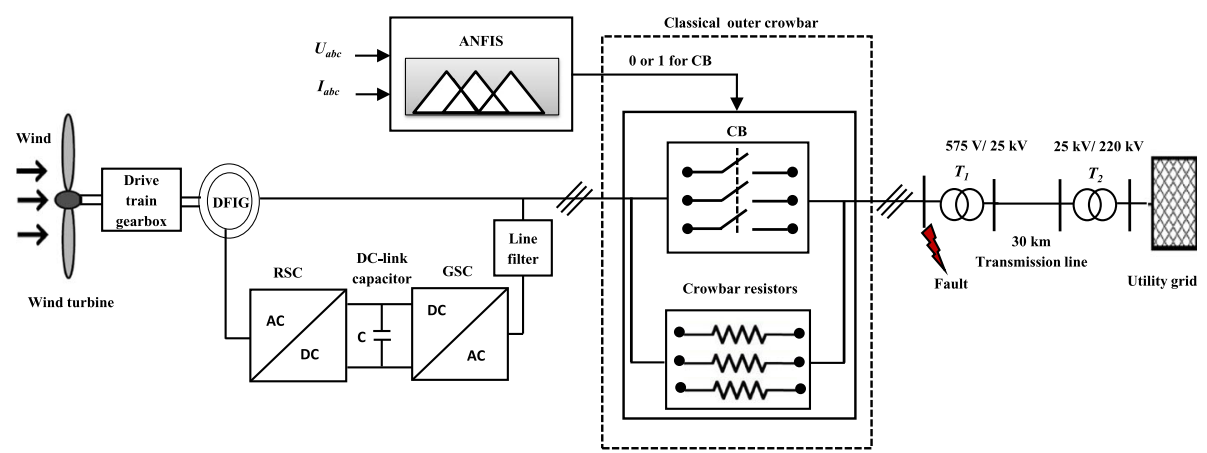

Fig. 2 Schematic diagram of DFIG wind turbine equipped with classical outer crowbar protection technique

protection technique is not classify the fault type. Thus, the operation mechanism of $\mathrm{CB}$ is not depending on fault type. Therefore, in the next subsection, the operation mechanism of $\mathrm{CB}$ is modified as a proposed protection technique to operate in different connection ways based on fault types.

\subsection{The methodology of proposed controllable CBFT protection technique driven by ANFIS}

The proposed ANFIS CBFT protection technique operates based on a new operation mechanism of a three single-phase $\mathrm{CBs}(\mathrm{CBa}, \mathrm{CBb}$, and $\mathrm{CBc})$ for phases $\mathrm{a}, \mathrm{b}$, and $\mathrm{c}$ respectively as shown in Fig. 5. Each controllable $\mathrm{CB}$ is connected in parallel with a crowbar resistor and all of them are connected in series to grid terminals. In normal conditions, all CBs remain closed and the currents are passing through them. During grid faults, the $\mathrm{CB}$ of any faulted phase is opened, then the current is passing through its crowbar resistor.

In the proposed controllable CBFT protection technique, the fault type detector and the operation mechanism of CBs are driven via ANFIS networks. A separated three ANFIS networks (ANFISa, ANFISb, and ANFISc) are used to detect the fault occurrence and classify it for

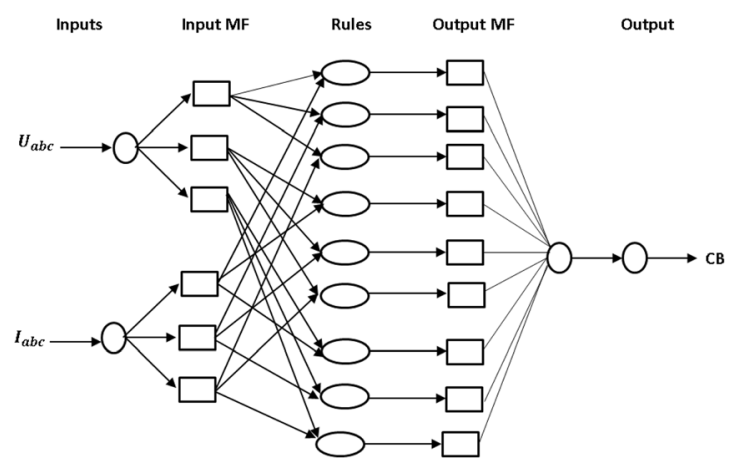

Fig. 3 ANFIS structure of classical protection technique for studied system phases a, b, and c respectively. As shown in Fig. 6, the inputs of each ANFIS network are the RMS values of voltage and current for each phase, where these inputs are measured at DFIG terminals. The inputs of ANFISa, ANFISb, and ANFISc are $\left(U_{a}, I_{a}\right),\left(U_{b}, I_{b}\right)$, and $\left(U_{c}, I_{c}\right)$ respectively. The output of each ANFIS network is a control signal that sending to the desired $\mathrm{CB}$ to activate or deactivate it. Therefore, the protection technique activates only the crowbar resistances of faulted phases. The outputs of ANFIS networks for all faults occurrence probabilities are given in Table 2. The flowchart of proposed technique for different fault types is illustrated in Fig. 7.

\section{Simulation results and discussion}

In this section, the dynamic performance of DFIG wind turbine equipped with the proposed CBFT protection technique during occurrence of symmetrical and

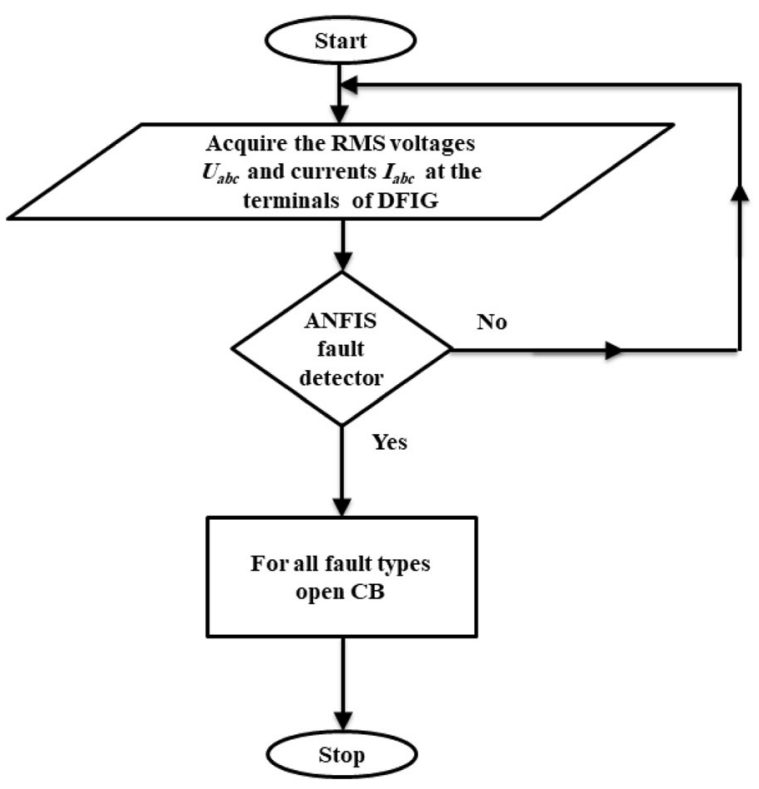

Fig. 4 Flowchart of classical outer crowbar protection technique using ANFIS network 


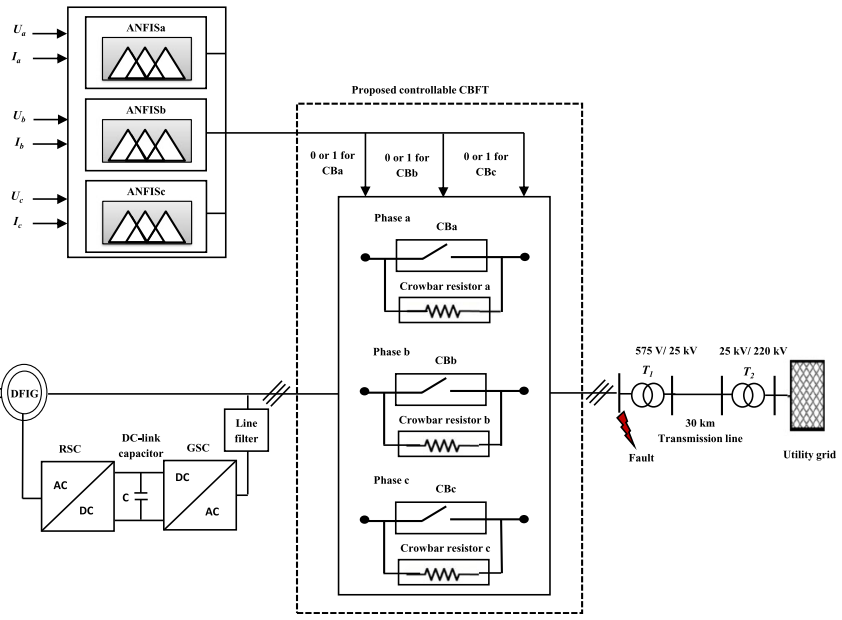

Fig. 5 Schematic diagram of DFIG wind turbine equipped with proposed ANFIS CBFT protection technique

unsymmetrical faults is investigated. The whole studied system consists of six 1.5 MW wind turbine generators connected to distribution system of $25 \mathrm{kV}$ and exports power to $220 \mathrm{kV}$ grid through transmission line of $30 \mathrm{~km}$ length as shown in Fig. 5. The wind turbine generator operates at wind speed of $10 \mathrm{~m} / \mathrm{s}$, where the maximum output power of wind turbine is $0.55 \mathrm{pu}$ of its rated power. During steady state conditions, the values of DC-link voltage, active power, and reactive power are
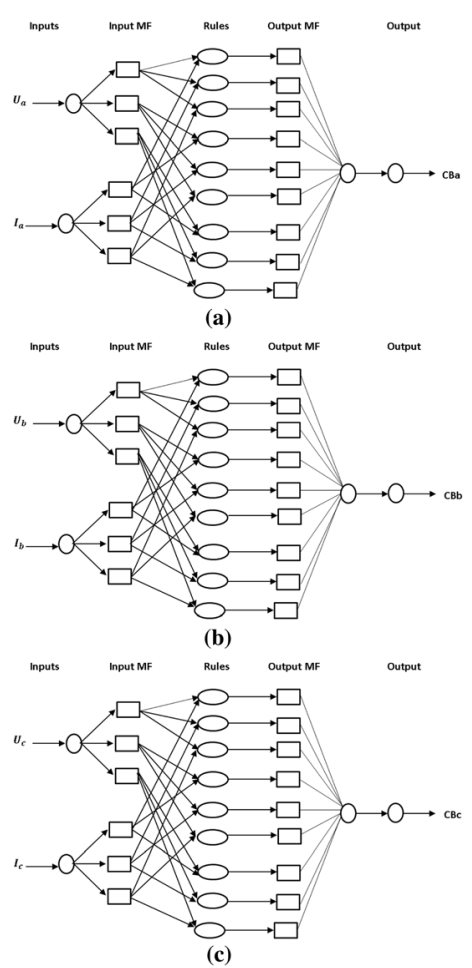

Fig. 6 ANFIS structures of proposed protection technique for studied system (a) ANFISa; (b) ANFISb; (c) ANFISC
$1200 \mathrm{~V}, 4.74 \mathrm{MW}$, and 0 MVAR respectively. The overall parameters of grid connected DFIG wind turbines are given in Table 3 . The studied faults are single-phase, double-phase, and three-phase to ground faults, these faults occur at terminals of wind turbines for a duration time of $150 \mathrm{~ms}$, where any fault occurs at $1.5 \mathrm{~s}$ and it is cleared at $1.65 \mathrm{~s}$ from simulation time. Figure 8 shows the terminal voltage variations of wind turbines equipped with proposed CBFT protection technique in cases of single-phase to ground fault, double-phase to ground fault, and three-phase to ground fault. Figure 8(a) shows that, the voltage of faulted phase a is decreased to $0.0159 \mathrm{pu}$ and the voltages of un-faulted phases $\mathrm{b}$ and $\mathrm{c}$ are increased to 1.705 and $1.871 \mathrm{pu}$ respectively during fault period of single-phase to ground fault. Figure 8(b) shows that, the voltages of faulted phases a and b are decreased to 0.08129 and $0.07213 \mathrm{pu}$ respectively and the voltage of un-faulted phase $\mathrm{c}$ is increased to $1.861 \mathrm{pu}$ during fault period of double-phase to ground fault. Figure 8(c) shows that, the voltages values of faulted phases a, b, and c are decreased to 0.087 pu during fault period of three-phase to ground fault.

Table $\mathbf{2}$ Grid fault type codes

\begin{tabular}{lllll}
\hline Faulted phases & \multicolumn{4}{l}{ ANFIS outputs } \\
\cline { 2 - 5 } & ANFISa & ANFISb & ANFISc & Fault type \\
\hline No fault & 0 & 0 & 0 & 0 \\
Phase a to ground & 1 & 0 & 0 & $1 \mathrm{a}$ \\
Phase b to ground & 0 & 1 & 0 & $1 \mathrm{~b}$ \\
Phase $\mathrm{c}$ to ground & 0 & 0 & 1 & $1 \mathrm{c}$ \\
Phases $\mathrm{a}$ and $\mathrm{b}$ to ground & 1 & 1 & 0 & $1 \mathrm{a}, \mathrm{b}$ \\
Phases $\mathrm{b}$ and $\mathrm{c}$ to ground & 0 & 1 & 1 & $1 \mathrm{~b}, \mathrm{c}$ \\
Phases $\mathrm{c}$ and $\mathrm{a}$ to ground & 1 & 0 & 1 & $1 \mathrm{c}, \mathrm{a}$ \\
Phases $\mathrm{a}, \mathrm{b}$, and $\mathrm{c}$ to ground & 1 & 1 & 1 & $1 \mathrm{a}, \mathrm{b}, \mathrm{c}$ \\
\hline
\end{tabular}




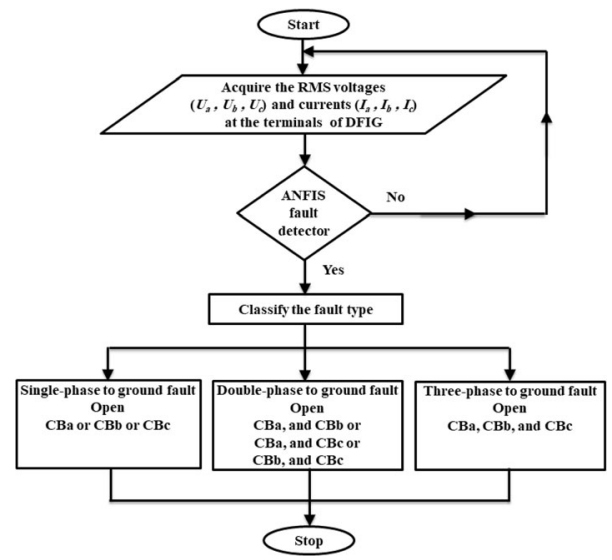

Fig. 7 Flowchart of proposed CBFT protection technique using ANFIS networks

\subsection{Impacts of different fault types}

The comparison between performance of DFIG wind turbine generators in case of using the classical outer crowbar and in case of using the proposed ANFIS CBFT protection techniques during different fault types is studied and illustrated in the following subsections. Also,

Table 3 Parameters of studied system

\begin{tabular}{ll}
\hline Parameters & Values \\
\hline The parameters of DFIG & 575 \\
Rated voltage $(\mathrm{V})$ & 1.5 \\
Rated power $(\mathrm{MW})$ & 60 \\
Rated frequency $(\mathrm{Hz})$ & 0.0050 \\
Rotor resistance $(\mathrm{pu})$ & 0.00706 \\
Stator resistance $(\mathrm{pu})$ & 2.9 \\
Mutual inductance $(\mathrm{pu})$ & 0.156 \\
Rotor leakage inductance $(\mathrm{pu})$ & 0.171 \\
Stator leakage inductance $(\mathrm{pu})$ & \\
The parameters of transmission line & 0.4131 \\
Zero sequence resistance $(\Omega / \mathrm{km})$ & 0.1154 \\
Positive sequence resistance $(\Omega / \mathrm{km})$ & $5.02 \mathrm{e}-9$ \\
Zero sequence capacitance $(\mathrm{F} / \mathrm{km})$ & $11.33 \mathrm{e}-9$ \\
Positive sequence capacitance $(\mathrm{F} / \mathrm{km})$ & 0.00331 \\
Zero sequence inductance $(\mathrm{H} / \mathrm{km})$ & 0.00105 \\
Positive sequence inductance $(\mathrm{H} / \mathrm{km})$ & \\
The parameters of transformer $(\mathrm{T} 1)$ & $0.00534+\mathrm{j} 0.16$ \\
Turns ratio & $575 \mathrm{~V} / 25 \mathrm{kV}$ \\
Impedance (pu) & $0.0017+\mathrm{j} 0.05$ \\
The parameters of transformer $(\mathrm{T} 2)$ & \\
Turns ratio & \\
Impedance (pu) & \\
The parameters of grid & \\
Impedance (pu) & \\
\hline
\end{tabular}
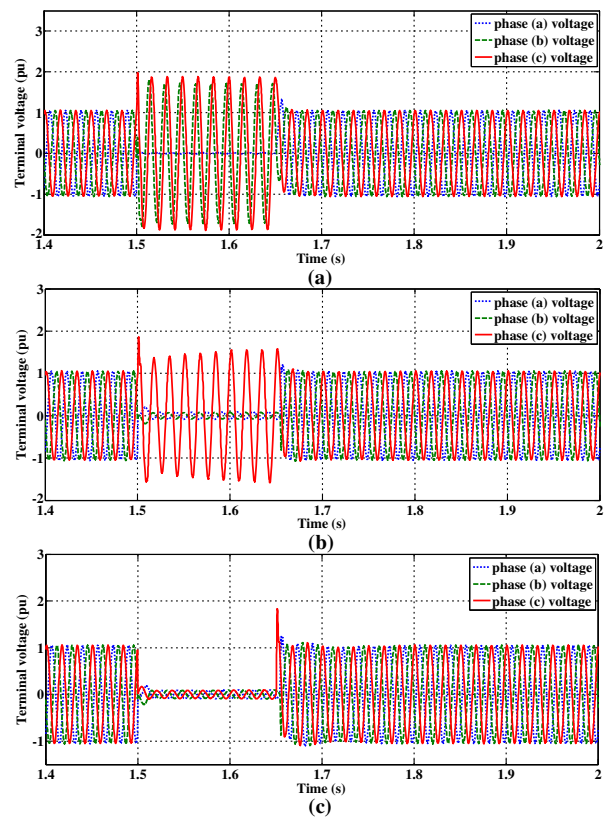

Fig. 8 Terminal voltage variations during different fault types (a) single-phase to ground fault; (b) double-phase to ground fault; (c) three-phase to ground fault

a comparison with traditional parallel rotor crowbar protection technique is investigated to demonstrate the effectiveness of the proposed technique. It is worth to be mentioned that, the operation mechanism of traditional parallel rotor crowbar protection technique as described in [10-14] is designed to deactivate the RSC during fault occurrence and the rotor windings are connected to the crowbar resistors instead of the converters.

\subsubsection{Impact of single-phase to ground fault}

During occurrence of single-phase to ground fault on phase a, the ANFIS network of classical outer crowbar protection technique detects the fault occurrence and sends a control signal to open the $\mathrm{CB}$, then the current will be flowing through the crowbar resistors. Otherwise, the proposed ANFIS CBFT protection technique detects the fault occurrence and classifies it, then a control signal is sending to open only $\mathrm{CBa}$ for faulted phase and the current will be flowing in crowbar resistor a. Figure 9 shows a comparison between the variations of DC-link voltage, active power, and reactive power during occurrence of single-phase to ground fault when the studied system is protected by traditional parallel rotor crowbar, classical outer crowbar, and proposed ANFIS CBFT protection techniques respectively. As is shown in Fig. 9(a), when the wind turbine generator is equipped with traditional parallel rotor crowbar protection technique, the DC-link voltage is decreased to $1187 \mathrm{~V}$ during fault period and increased to $1221 \mathrm{~V}$ after fault clearance, then it returns to steady state value of $1200 \mathrm{~V}$. Also, 

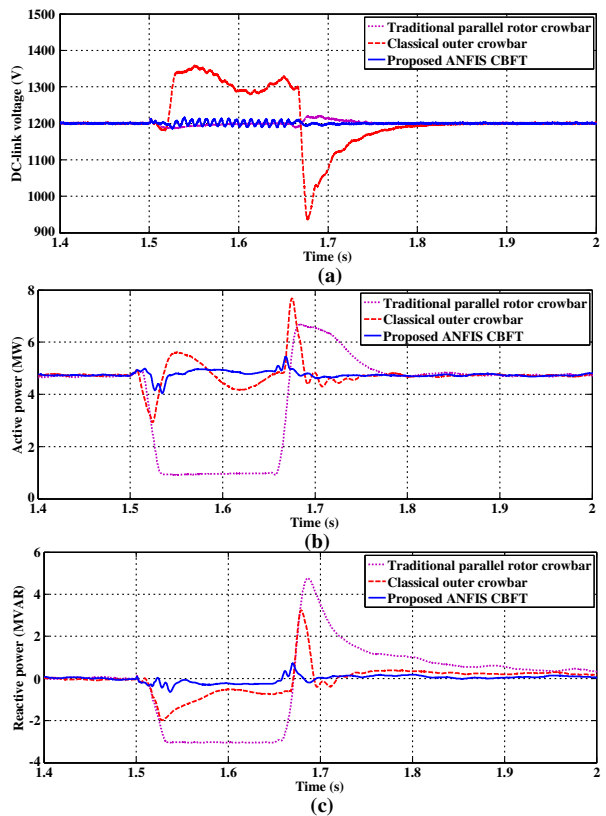

Fig. 9 Comparison of measured values for traditional, classical, and proposed protection techniques during single-phase to ground fault (a) DC-link voltage; (b) active power; (c) reactive power

when the wind turbine generator is equipped with classical outer crowbar technique, the DC-link voltage is increased to $1359 \mathrm{~V}$ during fault period and decreased to $935 \mathrm{~V}$ after fault clearance, then it returns to steady state value of $1200 \mathrm{~V}$. On the other hand, when the system is equipped with the proposed CBFT protection technique, the DC-link voltage is stable and has a little variation, where it is varied between 1193 and $1212 \mathrm{~V}$ during fault period. Figure 9(b) shows the comparison of active power variations in cases of using traditional parallel rotor crowbar, classical outer crowbar, and proposed CBFT protection techniques respectively. It is noticed that, when the wind turbine generator system is protected with traditional parallel rotor crowbar technique, the active power is decreased to $0.96 \mathrm{MW}$ after fault occurrence and increased to $6.68 \mathrm{MW}$ after fault clearance, then it returns to the steady state value. Also, when the wind turbine generator system is protected with classical outer crowbar technique, the active power is decreased to 2.94 MW after fault occurrence and fluctuated between 4.18 and $5.61 \mathrm{MW}$ during fault period, then it is increased to $7.68 \mathrm{MW}$ after fault clearance before it returns to the steady state value. Otherwise, with using the proposed CBFT protection technique, the active power is decreased to $4 \mathrm{MW}$ after fault occurrence and returns to steady state value during the rest time of fault period, then it is increased to $5.44 \mathrm{MW}$ after fault clearance before it returns to steady state value. Moreover, the delivered active power is more stable during fault period in case of using the proposed CBFT protection technique comparing with cases of using traditional and classical crowbar protection techniques. Figure 9(c) shows the variations of reactive power in cases of using traditional parallel rotor crowbar, classical outer crowbar, and proposed CBFT protection techniques respectively. It is obviously that, the reactive power is decreased to 3.04 MVAR after fault occurrence and increased to 4.77 MVAR after fault clearance in case of using the traditional parallel rotor crowbar technique, while it is decreased to - 1.99 MVAR after fault occurrence and increased to 3.24 MVAR after fault clearance in case of using the classical outer crowbar technique. On the other hand, it has a little fluctuation in case of using the proposed CBFT protection technique, where it is decreased to - 0.64 MVAR after fault occurrence and increased to 0.72 MVAR after fault clearance. Also, the absorbed reactive power during fault period in case of using the proposed CBFT protection technique is less than the absorbed reactive power in cases of using traditional and classical crowbar techniques.

\subsubsection{Impact of double-phase to ground fault}

The behaviours of studied wind turbine generators during occurrence of double-line to ground fault are studied when the fault occurs on phases a and b. the ANFIS network of classical outer crowbar protection technique detects the fault, then the $\mathrm{CB}$ is opened and the currents will be passing through the crowbar resistors for all faulted and un-faulted phases. Otherwise, the ANFIS networks of proposed CBFT protection technique detect the fault and classify its type, then a control signals are sending to open $\mathrm{CBa}$ and $\mathrm{CBb}$ for faulted phases and the current will be flowing in crowbar resistors a and $\mathrm{b}$. The variations of DC-link voltage, active power, and reactive power are indicated in Fig. 10. As is shown in Fig. 10(a), the variation of DC-link voltage with traditional parallel rotor crowbar technique is varied between 1491 and $1128 \mathrm{~V}$ after fault occurrence, also it is varied between 1179 and $1236 \mathrm{~V}$ after fault clearance. Otherwise, the variations of DC-link voltage with classical outer crowbar technique and with proposed CBFT protection technique are nearly identical. Thus, it is increased to $1482 \mathrm{~V}$ after fault clearance and fluctuated around the steady state value of $1200 \mathrm{~V}$ during fault periods, then it returns to the steady state values after fault clearance. As is shown in Fig. 10(b), the active power is more stable with proposed CBFT protection technique during fault periods. It is clear that, in case of using the traditional technique, the active power is decreased to $0.134 \mathrm{MW}$ during fault period and increased to $7.15 \mathrm{MW}$ after fault clearance. Otherwise, the active power is decreased to $1 \mathrm{MW}$ after fault occurrence in case of using the proposed CBFT protection technique, while it is decreased 

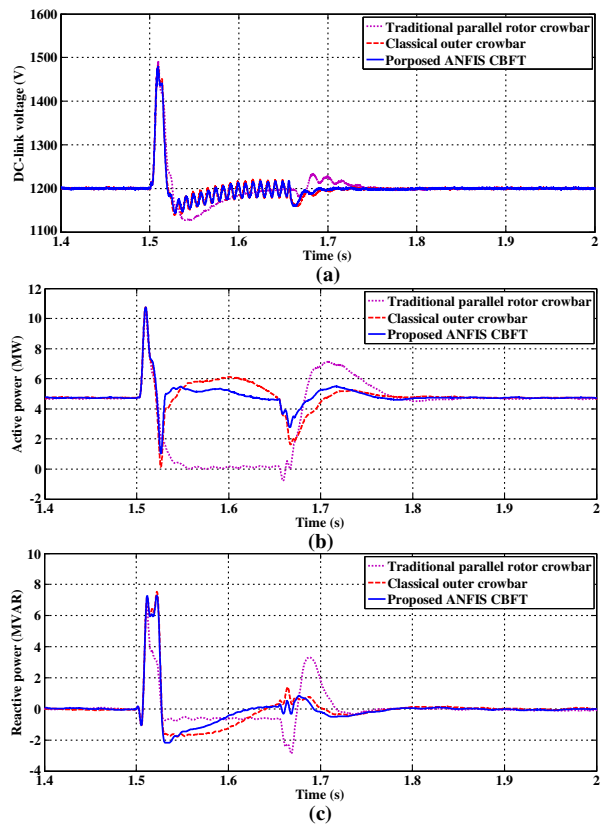

Fig. 10 Comparison of measured values for traditional, classical, and proposed protection techniques during double-phase to ground fault (a) DC-link voltage; (b) active power; (c) reactive power

to $0.14 \mathrm{MW}$ with the classical outer crowbar technique. Also, after fault clearance, the active power is decreased to $2.77 \mathrm{MW}$ with the proposed protection technique and decreased to $1.63 \mathrm{MW}$ with the classical outer crowbar protection technique. Figure 10(c) shows the reactive power variations, in case of using the traditional technique, the reactive power is decreased to -0.68 MVAR during fault period, then it is fluctuated between -2.88 and 3.29 MVAR after fault clearance. On the other hand, it is increased to 7.5 MVAR and decreased to -1.76 MVAR after fault occurrence in case of using the classical outer crowbar technique, while it increased to 7.3 MVAR and decreased to -2.2 MVAR in case of using the proposed CBFT protection technique. Moreover, during the rest time of fault period, the absorbed reactive power with proposed protection technique is less than the absorbed reactive power with the classical outer crowbar technique. After fault clearance, the reactive power is increased to 1.4 MVAR with the classical outer crowbar technique and it is fluctuated between 0.85 and - 0.32 MVAR with the proposed CBFT protection technique.

\subsubsection{Impact of three-phase to ground fault}

In case of using the proposed CBFT protection technique, the three-phase to ground fault is detected and classified, then a three control signals are sending to open $\mathrm{CBa}, \mathrm{CBb}$, and $\mathrm{CBc}$, while in case of using classical outer crowbar protection technique, the fault is detected and not classified, then one control signal is sending to open CB. Logically, the responses of studied system are identical when it is protected by proposed CBFT protection technique or classical outer crowbar protection technique. Figure 11 shows the variations of DC-link voltage, active power, and reactive power in case of three-phase to ground fault with different studied protection techniques. As is shown in Fig. 11(a), the DC-link voltage is increased to $1695 \mathrm{~V}$ and decreased to 977.5 V during fault period in case of using traditional parallel rotor crowbar protection technique. Otherwise, the DC-link voltage is fluctuated between 1735 and $1056 \mathrm{~V}$ after fault occurrence in cases of classical outer crowbar and proposed CBFT protection techniques. As shown in Fig. 11(b), the active power is increased to 8.6 MW and decreased to $0.443 \mathrm{MW}$ during fault period, while it is fluctuated between -2.6 and 7.12 MW after fault clearance in case of using traditional parallel rotor crowbar protection technique. On the other hand, the active power is fluctuated between 9.15 and $1.58 \mathrm{MW}$ after fault occurrence, while it is fluctuated between -3.15 and 6.56 MW after fault clearance, then it returns to the steady state value in cases of classical outer crowbar and proposed CBFT protection techniques.

As indicated in Fig. 11(c), the reactive power is increased to 5.9 MVAR and decreased to - 0.59 MVAR during fault period, while it is fluctuated between -2 and 3.5 MVAR after fault clearance in case of using traditional
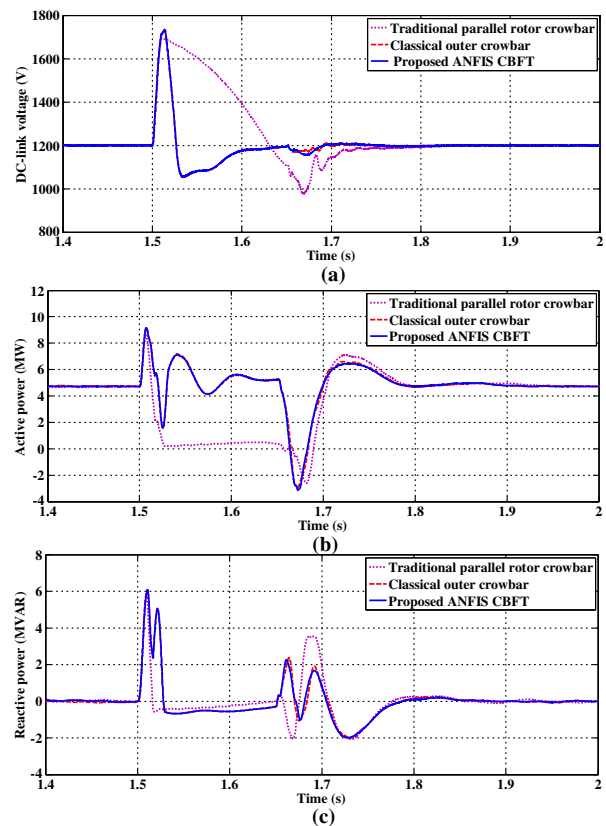

Fig. 11 Comparison of measured values for traditional, classical, and proposed protection techniques during three-phase to ground fault (a) DC-link voltage; (b) active power; (c) reactive power 
parallel rotor crowbar protection technique. Otherwise, in cases of classical outer crowbar and proposed CBFT protection techniques, the reactive power variation is fluctuated between 6.08 and 2.35 MVAR after fault occurrence, while during the rest time of fault period, the magnitude of it equals 0.56 MVAR nearly. Also, it is fluctuated between 2.35 and - 2 MVAR after fault clearance.

Finally, the operation of DFIG wind turbines in case of using the proposed ANFIS CBFT protection technique is more stable, where it can return to steady state conditions in a short time after fault clearance comparing with the traditional parallel rotor crowbar and classical outer crowbar protection techniques. The studied system is staying to deliver stable active power with proposed CBFT protection technique during fault period. Moreover, the variations of DC-link voltage, active power, and reactive power are decreased by using the proposed ANFIS CBFT crowbar protection technique. The proposed technique is more accurate in case of single-phase to ground fault considering this fault is the most frequently fault type that occurs in power system. The operation mechanism of proposed technique is designed based on fault type, where this fault is detected and classified using ANFIS networks. Also, the proposed technique inserts a specified crowbar resistor for faulted phases only to enhance the studied system stability.

\subsection{Impacts of crowbar resistance values}

The different impacts of crowbar resistance $R_{c}$ on the accuracy of proposed CBFT in the cases of single-phase,
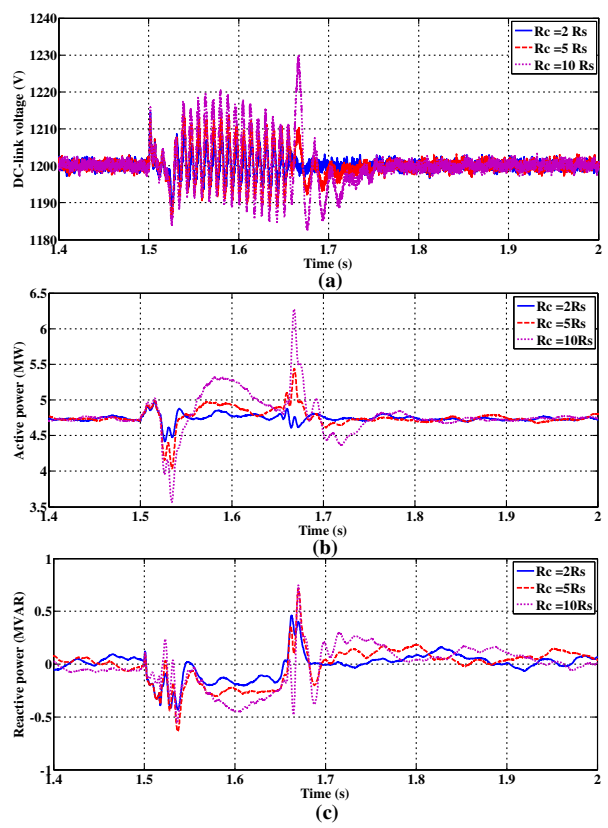

Fig. 12 Variation of measured values during single-phase to ground fault with different CBFT resistances (a) DC-link voltage; (b) active power; (c) reactive power double-phase, and three-phase to ground faults are investigated. The different values of $R_{c}$ are equal to 2,5 , and 10 times of stator resistance $R_{s}$. The variations of measured values of DC-link voltage, active power, and reactive power at different $R_{c}$ values are illustrated in Figs. 12, 13, and 14 for different fault types. It is clear that, the measured values are affected by the crowbar resistance value, thus the crowbar resistance value should be chosen carefully. Moreover, the stability of studied system equipped with the proposed CBFT protection technique is more stable in case of using $R_{c}$ equals 2 or 5 times of $R_{s}$.

\section{Conclusions}

This paper presents a novel ANFIS controllable CBFT protection technique to protect the DFIG wind turbines grid connected during different faults. The studied system has a total capacity of $9 \mathrm{MW}$, where it consists of six wind turbine generators with a capacity of $1.5 \mathrm{MW}$ for each of them. The proposed protection technique consists of three crowbar resistors, where each resistor is connected in parallel with a controllable single-phase $\mathrm{CB}$ and both of them are connected between the

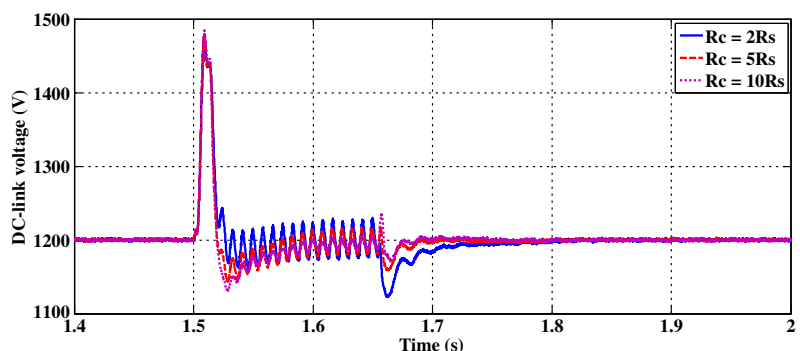

(a)

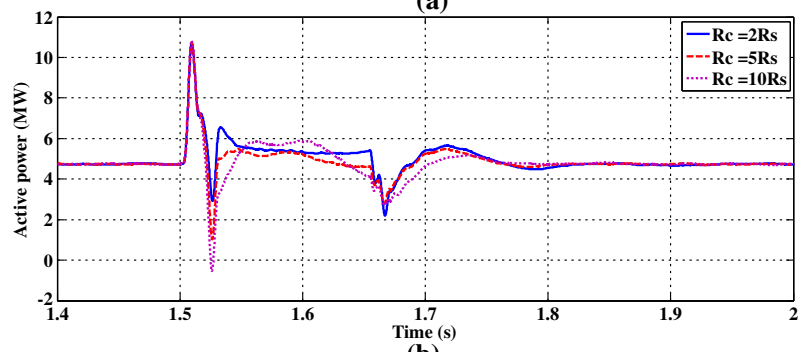

(b)

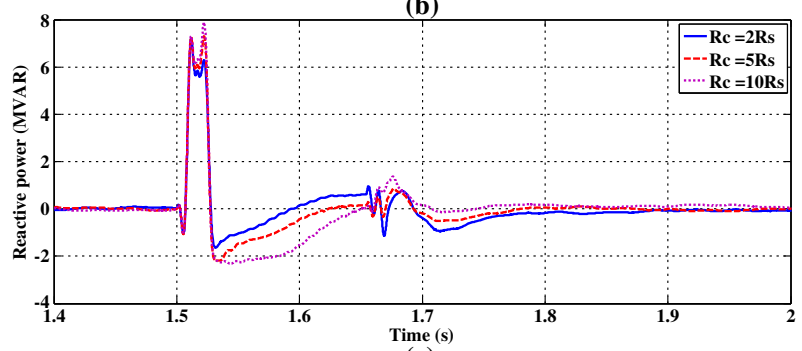

(c)

Fig. 13 Variation of measured values during double-phase to ground fault with different CBFT resistances (a) DC-link voltage; (b) active power; (c) reactive power 


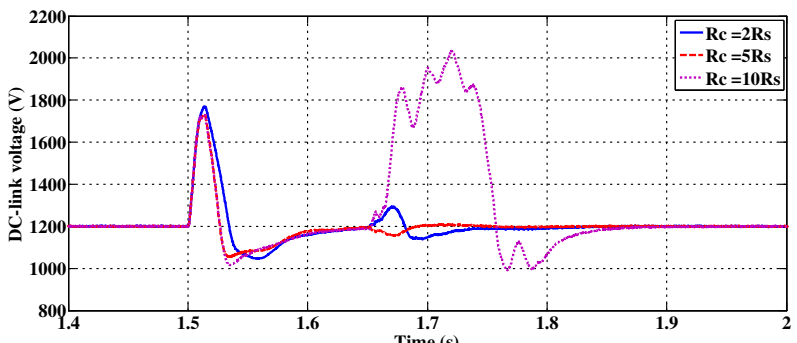

(a)

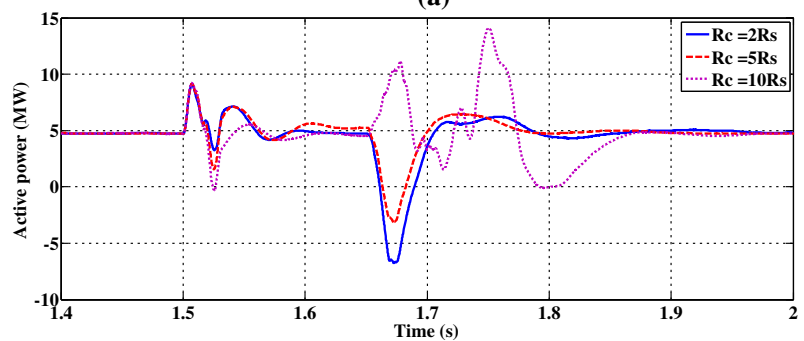

(b)

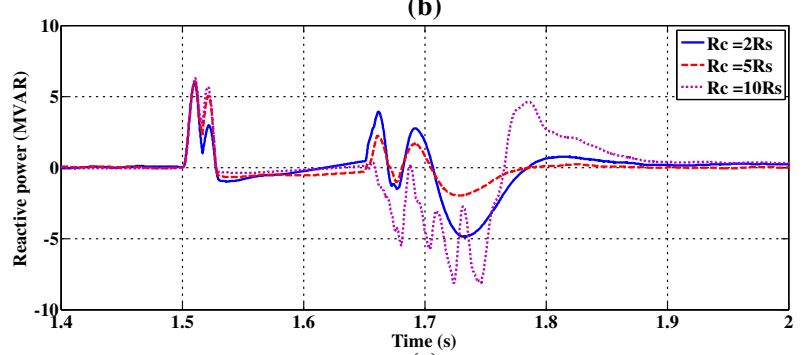

(c)

Fig. 14 Variation of measured values during three-phase to ground fault with different CBFT resistances (a) DC-link voltage; (b) active power; (c) reactive power

terminals of DFIG wind turbine and electrical grid. The ANFIS networks are used to detect and classify the fault types, then it sends a control signal to activate the specified CBs of faulted phases to protect the DFIG, DC-link capacitor, and converters from dangerous effects. The accuracy of proposed protection technique is investigated during different fault types such as single-phase to ground fault, double-phase to ground fault, and three-phase to ground fault. The variations of DC-link voltage, active power, and reactive power during occurrence of different fault types are investigated when the studied system is equipped with proposed protection technique and when it is equipped with classical outer crowbar protection technique. Also, a comparison with traditional parallel rotor crowbar protection technique is investigated to demonstrate the effectiveness of proposed technique. The simulation results show that, the variations of measured DC-link voltage, active power, and reactive power during fault periods are more stable and have little fluctuations when the wind turbine generators are equipped with proposed CBFT protection technique. The reduction of fluctuations when the studied system is equipped with proposed CBFT protection technique is more obvious in case of single-phase to ground fault considering this fault is the most frequently fault type that occurs in power systems. Also, the impacts of different crowbar resistance values on the behaviour of studied system and the accuracy of proposed protection technique are investigated. Finally, the results show that the proposed CBFT protection technique based on ANFIS has obvious effect for enhancing the stability of studied system.

\section{Availability of data and materials}

Data sharing not applicable to this article as no datasets were generated or analyzed during the current study.

\section{Authors' contributions}

ON suggested the idea of the proposed protection technique. ON carried out the MATLAB model for studied wind energy conversion system. ON and $\mathrm{IH}$ carried out the ANFIS protection technique algorithms. ON and $\mathrm{IH}$ participated in result analysis and discussion. Both authors read and approved the final manuscript.

\section{Competing interests}

The authors declare that they have no competing interests.

Received: 6 August 2018 Accepted: 18 September 2018

Published online: 16 October 2018

\section{References}

1. Dash, P. K., Patnaik, R. K., \& Mishra, S. P. (2018). Adaptive fractional integral terminal sliding mode power control of UPFC in DFIG wind farm penetrated multimachine power system. Protection and Control of Modern Power Systems, 3(8), 1-14.

2. Boubzizi, S., Abid, H., El hajjaji, A., \& Chaabane, M. (2018). Comparative study of three types of controllers for DFIG in wind energy conversion system. Protection and Control of Modern Power Systems, 3(21), 1-12.

3. Benbouzid, M., Muyeen, S., \& Khoucha, F. (2015). An up-to-date review of low-voltage ride-through techniques for doubly-fed induction generatorbased wind turbines. International Journal of Energy Conversion, 1(3), 1-9.

4. Jadhav, H. T., \& Roy, R. (2013). A comprehensive review on the grid integration of doubly fed induction generator. International Journal of Electrical Power \& Energy Systems, 49, 8-18

5. Xie, D., Xu, Z., Yang, L., Østergaard, J., Xue, Y., \& Wong, K. P. (2013). A comprehensive LVRT control strategy for DFIG wind turbines with enhanced reactive power support. IEEE Transactions on Power Systems, 28(3), 3302-3310

6. Wang, Y., Phung, B. T., \& Ravishankar, J. (2015). Fault analysis of an islanded microgrid with doubly fed induction generator based wind turbine. In Proceedings of international conference on electricity distribution (pp. 1-5). Lyon: CIRED.

7. Dami, M. A., Jemli, K., Jemli, M., \& Gossa, M. (2010). Doubly fed induction generator, with crow-Bar system, under micro-interruptions fault. International Journal on Electrical Engineering and Informatics, 2(3), 216-231.

8. Tremblay, E., Atayde, S., \& Chandra, A. (2011). Comparative study of control strategies for the doubly fed induction generator in wind energy conversion Systems : A DSP-based implementation approach. IEEE Transactions on Sustainable Energy, 2(3), 288-299.

9. Ren, Y., \& Zhang, W. (2011). A Novel Control Strategy of an Active Crowbar for DFIG-Based Wind Turbine during Gird Faults. In: Proceedings of IEEE (pp. 1137-1142). Niagara Falls: International Conference on Electric Machines \& Drives (IEMDC)

10. Ling, Y. (2016). The fault ride through technologies for doubly fed induction generator wind turbines. Wind Engineering, 40(1), 31-49.

11. Pannell, G., Atkinson, D. J., \& Zahawi, B. (2010). Minimum-threshold crowbar for a fault-ride-through grid-code-compliant DFIG wind turbine. IEEE Transactions on Energy Conversion, 25(3), 750-759.

12. Yang, S., Zhou, T., Sun, D., Xie, Z., \& Zhang, X. (2016). A SCR crowbar commutated with power converter for DFIG-based wind turbines. International Journal of Electrical Power \& Energy Systems, 81, 87-103. 
13. Noureldeen, O. (2012). Behavior of DFIG wind turbines with crowbar protection under short circuit. International Journal of Electrical \& Computer Sciences IJECS-IJENS, 12(3), 32-37.

14. Noureldeen, O., \& Hamdan, I. (2017). An Efficient ANFIS Crowbar Protection for DFIG Wind Turbines during Faults. In Proceedings of IEEE (pp. 263-269). Cairo: Nineteenth International Middle East Power Systems Conference (MEPCON).

15. Noureldeen, O. (2012). A novel crowbar protection technique for DFIG wind farm during fault ride through. International Journal of Engineering \& Technology IJET-IJENS, 12(3), 85-95.

16. Hu, S., Zou, X., \& Kang, Y. (2014). A novel optimal design of DFIG crowbar resistor during grid faults. In Proceedings of IEEE (pp. 555-559). Hiroshima: International Conference on Power Electronics (IPEC-ECCE ASIA)

17. Salles, M. B. C., Hameyer, K., Cardoso, J., Grilo, A. P., \& Rahmann, C. (2010). Crowbar system in doubly fed induction wind generators. Energies, 3, 738-753.

18. Rahmann, C., Haubrich, H. J., Moser, A., Palma-Behnke, R., Vargas, L., \& Salles, M. B. C. (2011). Justified fault-ride-through requirements for wind turbines in power systems. IEEE Transactions on Power Systems, 26(3), 1555-1563.

19. Radojevic, Z. M., \& Shin, J. (2006). New one terminal digital algorithm for adaptive reclosing and fault distance calculation on transmission lines. IEEE Transactions on Power Delivery, 21(3), 1231-1237.

20. Parmar, S. (2015). Fault location algorithms for electrical power transmission lines methodology, design and testing. Master Thesis. Delft University of Technology, Netherlands

21. Bilgehan, M. (2011). Comparison of ANFIS and NN models-with a study in critical buckling load estimation. International Journal of Applied Soft Computing, 11(4), 3779-3791.

22. Taheri, H., Sodoudi, S., Kerschbaumer, A., \& Cubasch, U. (2015). A new structure identification scheme for ANFIS and its application for the simulation of virtual air pollution monitoring stations in urban areas. Engineering Applications of Artificial Intelligence, 41, 175-182.

23. Jamali, A., Babaei, H., Nariman-Zadeh, N., Ashraf Talesh, S. H., \& Mirzababaie Mostofi, T. (2016). Multi-objective optimum design of ANFIS for modelling and prediction of deformation of thin plates subjected to hydrodynamic impact loading. Journal of Materials: Design and Applications, 1-11. https:// doi.org/10.1177/1464420716660332.

24. Zheng, D., Eseye, A. T., Zhang, J., \& Li, H. (2017). Short-term wind power forecasting using a double-stage hierarchical ANFIS approach for energy management in microgrids. Protection and Control of Modern Power Systems, 2(13), 1-10.

25. Noureldeen, O., \& Hamdan, I. (2018). Design of robust intelligent protection technique for large-scale grid-connected wind farm. Protection and Control of Modern Power Systems, 3(17), 1-13.

26. Rahimi, M., \& Parniani, M. (2010). Grid-fault ride-through analysis and control of wind turbines with doubly fed induction generators. International Journal of Electric Power Systems Research, 80, 184-195.

27. Tamaarat, A., \& Benakcha, A. (2014). Performance of PI controller for control of active and reactive power in DFIG operating in a grid-connected variable speed wind energy conversion system. Frontiers in Energy, 8(3), 371-378.

28. Li, S., Haskew, T. A., Hong, Y.-K., \& Mazari, S. (2010). Integrating electrical and aerodynamic characteristics for DFIG wind energy extraction and control study. International Journal of Energy Research, 34, 1052-1070.

29. Dida, A., \& Benattous, D. (2016). A complete modeling and simulation of DFIG based wind turbine system using fuzzy logic control. Frontiers Energy, 10(2), 143-154.

30. Little, M., \& Pope, K. (2017). Performance modelling for wind turbines operating in harsh conditions. International Journal of Energy Research, 41, $417-428$.

\section{Submit your manuscript to a SpringerOpen ${ }^{\circ}$ journal and benefit from:}

- Convenient online submission

- Rigorous peer review

- Open access: articles freely available online

- High visibility within the field

- Retaining the copyright to your article

Submit your next manuscript at $\boldsymbol{\nabla}$ springeropen.com 